\title{
Counseling: A Misunderstood Profession
}

\author{
Mahalakshmi Rajagopal \\ Counselor, O P Jindal global University, Sonepat, Haryana
}

\begin{abstract}
Counseling is a very commonly used term in India. How it is being used and for what, is a matter of discussion. This aspect is extremely important to understand the status of therapeutic / psychological / clinical counseling in India.

This paper is a study of people's perception about this profession based on the author's experiences as a counselor in schools and college as well as in private practice. The objective of the paper is to elaborate on the profession as perceived in India and make an attempt to understand where the country stands with regard to counseling through intensive review of literature. This would enable the author as well as the readers to understand the progress made as well as the progress required. The paper also discusses the role of this profession in mental well being of common man.

The paper would also carry a few case studies from the author's professional experience. The paper would conclude with suggestions and recommendations for a better standing for this profession in India.
\end{abstract}

Key Words:Counseling, case studies, documentation, research, techniques

\section{Introduction}

Counseling is defined as an interactive process conjoining the counselee who needs assistance and the counselor who is trained and educated to give this assistance .(Perez,1965).

Smith(1995) defines counseling as a process in which the counselor assists the counselee to make interpretations of facts relating to a choice, plan, or adjustments which he needs to make .

Counseling is also defined as a process which takes place in a one to one relationship between an individual beset by problems with which he cannot cope alone and a professional worker whose training and experience have qualified him to help others reach solutions to various types of personal difficulties(Hahn and MacLean,1955).

Effective counseling consists of a definitely structured permissive relationship which allows the client to gain an understanding of himself to a degree which enables him to take positive steps in the light of his new orientation. There was a college student who underwent a couple of sessions in his college with his college counselor. He approached her because he felt he had a severe inferiority complex. But during the sessions, he discovered that beneath his inferiority complex, lay an arrogant individual. This revelation helped him to chalk out specific steps to work and change himself .

A recent description of counseling psychology (APA, 1999) defines the specialty in part: "Counseling psychologists help people with physical, emotional, and mental disorders, improve well-being, alleviate distress and maladjustment, and resolve crises. ... Practitioners provide assessment, diagnosis, and treatment of psychopathology" (p. 589). Although the complete definition is very expansive, prevention is not directly stated as an area of expertise or study. The focus is definitely on remediation and corrective activities.

A young girl who has broken away from abusive relationship seeks the help of her college counselor to overcome the emotional trauma resulting from the abuse. This comes in as a remediation. But such a trauma may be avoided if individuals seek preventive help.Students , most of the time, both in school and college seek counseling services only as remedial therapy.

\section{Objective Of Counseling}

The major objective of counseling is to help individuals become self sufficient, self dependent, self directed and to adjust themselves efficiently to the demands of a better and meaningful life. Individuals are provided assistance to enhance their personal, social, emotional and intellectual development. Therefore the counselor's services are preventive, developmental and therapeutic in nature .Conyne (1991) argued that primary prevention strategies and training need to be given major priority within counseling because the efficacy of primary prevention programs has been demonstrated. Preventive counseling is still unheard of in India. It is important counselors are also skilled in group therapy and utilize the same for educative sessions for students and for the youth on various issues such as addiction, abusive relationship, marriage, better academic performance. Such programs fail to gain popularity because very often individuals do not consider the need 
for preventive measures for many of these intangible issues and maintain a "not for me " attitude. Many awareness programmes for parents on behavior problems of children conducted in schools has a very thin attendance. Many a time when interactive sessions are conducted for students with an aim to educate them about various emotional blocks, the session are taken very lightly and this atmosphere prevents even those students who wish to seek help from opening up for fear of being teased. Similarly such sensitization programmes may be conducted for the employees in corporate set up that will enable them to become aware of certain issue to be worked on for a better happier living .Such things may be considered as preventive group counseling sessions . Researchers have examined a constellation of core values which describe professional counseling as oriented toward: health and wellness (Myers, 1992); prevention and education (Kleist \& White, 1997; Lanning, 1990); guidance and humanism (Neukrug, 2003); normal human growth and development (Gale \& Austin, 2003); multiculturalism (Sue \& Arredondo, 1992); and social justice and advocacy (ACA, 2008). Indian counselors mostly play the role in education, general wellness and guidance. The same is often experienced by counselors in colleges where students meet the counselor to discuss and seek an approval /reaffirmation for their line of thought. These meetings need not necessarily be considered as "counseling sessions" but the students feel the need for such an individual, who is a non faculty who can and does understand them and interact with them respecting their individuality.

Counseling as a therapeutic technique, is based on the various theories of Freud, Adler, Watson, Rogers, Albert Ellis, Victor Frankl and others. Today, most professionals prefer to use client centered therapy and follow the Cognitive Behaviour Therapy which has its origin in Albert Ellis's theory of Rational EmotiveBehaviour Therapy, while following an eclectic approach where the various schools of counseling are taken in to consideration and the best techniques of each are used in a positive combination for the benefit of the client. Eclectic approach may be followed by those professionals who are skilled in practicing different schools of thought. This calls for not only for a flexibility in one's approach , but also an adeptness to be able to use an appropriate therapy for the appropriate individual. The same requires a therapy friendly environment and specific time schedules .

Counseling may be handled by individuals who are adequately qualified and have some practical experience in the field. It is also essential that the professional has other necessary attributes required to handle individual cases. Counseling in educational institutions are hampered because of lack of adequate time, irregular follow up and lack of suitable set up /environment. Students who approach the counselor expect a quick fix solution and are reluctant to make repeated visits due to lack of time," their seeking help getting known to others", inability to self reflect, inhibition to have regular sessions.

\section{Counseling in India}

In the past, India, with the joint family system being part and parcel of the culture, an individual's emotional and other personal problems were taken care of by the family members. The methodology followed was simply advice based on their own life experiences. While it helped many a time, there would be times when the advice was not helpful but the same was never conveyed to anyone. The basic belief followed by one and all wasthat the eldersof the family were always right and convinced them to turn self reflective rather than critical of the advice imparted. With passing of time, urbanization and industrialization brought in huge changes in the Indian society and in turn in the familystructure. Joint families disintegrated and gave room to nuclear families . Today single parent families too are not uncommon. These changes brought along with it ,growth and development as well as adjustment problems. Problems crept into various areas of life- personal as well as professional. There were no elders to sort out issues. Others did not seem to have the time nor the inclination to help or advice. Simultaneously the common man began to seek professional assistance for his problems and counseling as a profession began to find its roots and grow.

But counseling as a profession is still in its nascent stage in India. The common man is yet to understand the concept of approaching a professional to sort out his problems. There is still a lot of confusion as to what is counseling; why it is a paid service; why only certain individuals are considered eligible for the profession. The confusion is increased by the term counseling being used in various contexts. Students who are being admitted to colleges have " counseling". This session is simply an interview for checking documents and allocation of stream . People who seek the guidance of a dietician undergo diet counseling..

While the Central Board of Secondary Education ( CBSE) has made it mandatory for schools to appoint counselors, colleges and Universities too are taking steps to appoint counselors. Many corporates are also following suit. But the stigma attached to this profession continues and there is a huge indecisiveness with regard to the qualification prerequisites of a counselor. The role of school counselor is to essentially aid in identification of learning disabilities and also assist children with behavior problems while also working on prevention of inculcating problem behavior. Many schools expect the special educators to play the role of a counselor. There are still other schools that simply appoint an experienced teacher as a counselor. This is because of a poor awareness about counseling as an intervention which requires a specific education and 
practiceto obtain desired results .In most official set ups, counseling is merely considered " talking" and as a result neither is the professional appreciated nor are the interventions given importance. It is also important that the functions of counselors are clearly defined in educational settings . Most schools counselors are given extra duties and duties involving public relation activities. This reduces the time they spend with children in school and reduces opportunities for children to approach her .

Many a time, school counseling sessions are used to convince the parents / student that he / she needs to change the school because of the child's poor performance. Referral to a counseling session is generally used as a threat to students with bad behavior as a result of which the student does not perceive the counselor or the session as providing him/ her a scope for progress/ improvement in behavior or development of personality. In different institutions, counseling is insisted up on as part of disciplinary action and in such cases students are compelled to visit the counselor . Receptivity in such cases is very low and the visit is merely a formality. Most of the time teachers feel they can handle the students and that their advices are sufficient for bringing about a change in behavior and refrain from referring the student to the school counselor. Many students and parents associate meeting with a counselor to labeling a child as learning disabled and hence resent any referrals .Teachers are also hesitant to refer poor performers to the counselor as they will miss the classes and continue to lag behind. Many parents are defensive of their children or they themselves, being referred to the school counselor and consider the same very humiliating, while there are a good number who feel they can utilize the session to air their disgruntlement about the staff or faculty.

In a college set up, students are reluctant to open up to the counselor as they are very unsure about the issue of confidentiality. Many a time, the wardens or mentor faculty play the role of counselor and although the advices may be well meant, it may not really measure up equal to the services provided by a professional counselor.

In cases of adults too, there are lot of inhibitions in approaching a counselor as they are very unsure regarding the concept of confidentiality. Many a time couples approach a counselor hoping that the other partner will be " convinced" to change or improve his / her behavior. Many individuals meet a counselor with a particular set of ideas and expect just a reinforcement for the same irrespective of the consequences of the implementation of the idea. Adults are also confused with terms such as hypnosis/ regression / therapy and hence refrain from utilizing the services .

\section{Blocks In Counseling}

A universal recognition of this profession as one providing mental health service is essential . The 2005 publication, Mental Health Atlas by the World Health Organization (WHO) did not identify counselors as one of the helping professionals providing mental health services(Wendy J. Hoskins and Holly C. Thompson,2009). The professionals in this profession, irrespective of the stream they come from, be it, psychology or social work require some authentication from a statutory body that will endorse their professional skills. Although, in India, many opt for RCI registration, the same does not certify anybody per say as a counseling professional but only provides certification in the field of disability. A licensed professional holds a better standingin the society and it also ensures certain degree of professional recognition. Many Universities not recognized by the RCI are highly respected Universities approved by the U G C offering courses in Psychology, Counseling and Social Work . Hence there area lot of lacunae with regard to recognition and acceptance of this profession. Secondly, as this clinical practice focuses on enabling changes and transformation of personalities of clients, the practitioners require to be trained in self enhancement as it is essential that the professionals who enable transformation are themselves in a conscious process of self evolvement. Weinrach et al, (2001) described this professional identity as a core set of values, attitudes, and beliefs, a shared worldview, and unique behaviors that differ from other professions. But the course curriculum of counseling psychology does not necessarily focus on self evolvement .

Counseling and psychotherapy have been described as "potentially difficult, embarrassing, and overall risky enterprise[s . . . that induce] fear and avoidance in some individuals" (Kushner \&Sher, 1989, p. 256). Consistent with this statement, less than one third of individuals who experience psychological distress seek help from a mental health professional (Andrews, Issakidis, \& Carter, 2001). In fact, people tend to see counseling as a last resort (Hinson\& Swanson, 1993), something to be considered only after their attempts to handle things on their own or in consent with individuals close to them have failed (Wills, 1992). These perceptions of counseling persist, despite studies showing that seeking counselingservices is often helpful (Bergin \& Garfield, 1994) and that the consequences for not seeking help are often severe (Dubow, Lovko, \&Kausch, 1990). Thus, there is a need to clearly identify the factors that lead individuals to avoid seeking professional help (David L. Vogel et al,2007). Kushner and Sher(1989) found that individuals who needed counseling or psychotherapy but had not sought it had the highest level of treatment fears, suggesting that avoidance factors can inhibit help-seeking behavior even for individuals who could benefit from treatment. It seems, therefore, that many individuals perceive the act of seeking counseling or psychotherapy as a dilemma; although they are experiencing negative emotional, interpersonal, or psychological consequences, the thought of 
seeking help carries with it a negative perception, which may, in fact, be perceived as worse than the problem. Presently, as this paper is being conceptualized, there is a girl student suffering because of an abusive relationship. Although she has been referred to the counselor by her hostel warden and the girl herself has a good rapport with the college counselor, she is hesitant to seek help and avoids meeting the counselor.

Five factors have been described recently as avoidance factors in the help-seeking process: social stigma (Komiya et al, 2000), treatment fears (Deane \& Todd, 1996; Kushner\&Sher, 1989), fear of emotion (Komiya et al., 2000), anticipated utility and risks (Vogel \&Wester, 2003; Vogel, et al, 2005), and self-disclosure (Hinson \& Swanson, 1993; Vogel \&Wester, 2003). More than $90 \%$ of the sample in a study conducted by Nelson \&Barbaro, 1985 revealed that the fear that they would be thought of as crazy was a potential barrier to seeking help. This factor is very true in the Indian scenario. Many teenagers in school express their fear of being teased as "mad" because they meet the school counselor . Many parents even take offense when their child is referred to the school counselor. In any educational set up- school or college, students are not convinced about the confidentiality being maintained and hesitate to open up for fear of the facts reaching their faculty/ teacher. This attitude also prevents many from seeking help .

Treatment fears seem to have a greater effect on individuals dealing with such issues as (a) academic problems (Cepeda-Benito \& Short, 1998), (b) interpersonal problems (Vogelet al., 2005), and (c) drug/alcohol problems (Vogel et al., 2005), but have less of an effect for other issues, such as emotional problems or thoughts of suicide (Deane \& Todd, 1996). Clearly, treatment fears are an important avoidance factor, but more information is needed about their role relative to other factors. Persons who were less skilled at dealing with emotions have also been found to be less likely toseek help, in general, as well as less likely to seek help from a mental health professional for concerns about suicide (Ciarrochi\& Deane, 2001). Vogel and Wester (2003) found that expectations of having to express emotions to a therapist affected individuals' help-seeking attitudes and intentions. Vogel et al. (2005) found that expectations about emotional expression affected not only helpseeking attitudes and intentions but also actual help-seeking behavior.Anticipated utility refers to the perceived usefulness or lack thereof regarding seeking services from a counselor. Researchers (e.g., Tinsley et al., 1984) have suggested that individuals who donot seek counseling services may have lower expectations about the benefits of seeking help than do individuals who seek such services. The individual's perception of the utility of the service is directly responsible for the person's opinion about the service. Once when a faculty going through emotional stress was suggested that he meet the counselor, he refused saying that he was not comfortable with her. His response indirectly indicated that the counselor was not effective in building a rapport with her client .Later, it was discovered that this faculty had never met the counselor and did not know her at all. The response was his way of avoiding seeking help as he was unsure of the utility. Many a student in to habits of drugs / alcohol are reluctant to approach the counselor for overcoming the same due to fear of the consequences of opening up to the counselor. They prefer to shy away from sessions due to fear of suspension and other punishment actions which they believe will be meted out to them as a result of the counselor conveying their confessions to the management.

Anticipated risk, on the other hand, refers to an individual's perception of the potential dangers of opening up to another person (Vogel \&Wester, 2003). By seeking help from someone, the person risks feeling "misunderstood ... judged, or even ignored" (Harris et al, 1999, p. 407) and, thus, may choose not to seek help. The above mentioned example holds good for the fear of anticipated risk also.

Jourard (1964) described how the ability to self-disclose to another is central to a person's decision to seek help because in order to be helped, the person must choose to reveal to another person private feelings, thoughts, and attitudes. Very often students who have identified the need for their friend to meet the counselor are faced with a dilemma as to how to suggest the same to the friend in distress and fear a break in their relationship and prefer to keep quiet. Such decisions can be disastrous. Many a time, parents, siblings and friends request the counselor not to reveal her identity as a counselor. There have also been requests to meet in a non professional setting. These situations and experiences further validate the various causes explained above. Such experiences also calls for a general awareness with regard to the professionalism required in this profession.

Bayer and Peay (1997) and Vogel et al. (2005) found that people reported greater intent to seek professional help when they believed that important people in their lives would approve such an action. Diala et al. (2000) found that individuals who would be embarrassed if friends knew they sought care were 3 times less likely to seek care. This is mostly the reason for girls in abusive relationship to refrain from seeking help as their partner generally dissuades them from the same. Many a time, friends accompany the individual in trouble and motivate him/ her to seek the help of the counselor. This experience is common in college and school set up. Research studying the professional roles of counseling psychologists has revealed that prevention is tangential to the major activities of counseling psychologists. Fretz and Simon (1992) examined several survey studies on how counseling psychologists spend their professional time and concluded that "there is consistent evidence that far more time is being spent on remedial, therapeutic activities than on the preventive and developmental/educational activities that have long been identified as major themes in the profession. 


\section{The Need For Change In Indian Counseling}

Indian counselors require to opt for certain quantitative assessment tools to supplement their diagnosis. Counseling is a specialized profession which involves introduction of various interventions and the effectiveness and success of the same lies in the receptivity and usage by the client. In such cases, evaluation of success of this work becomes difficult. However, Greg Brigman and Chari Campbell (2003) conducted a study to evaluate the effectiveness of counseling in schools which focused on group counseling and class room guidance using a student success skills model that had been developed based on various reviews of research .

The study was conducted for a period of two years and aimed to determine if school counselor led interventions had a positive impact on student achievement and school success behaviours. The results revealed that student counselor led intervention combined with class room guidance had a positive impact on students achievement and behavior. At the same time, they also recommend that it is essential that more studies be conducted in this area for which it is essential that counselors use methods to measure and report impact of their services. This kind of practice is sadly lacking in Indian schools. Neither are assessment tools provided in schools nor can they be used as many counselors arejust experienced teachers .

Robert JPetrella (2002), conducted a study to determine the effect of counseling patients to become more physically active. They discovered that interventions were effective at increasing levels of physical activity but also were faced with the question regarding the cost effectiveness of the counseling program as many a time they felt the steps taken to make the patients physically active proved to be much costlier than what the patients were when they were not in to physical activity . Shortcomings of these studies include lack of long-term data, lack of sustaining activities for family physicians, and scant cost-efficacy analysis. Counseling in hospitals by specialized professionals is still an unfamiliar concept in India.

Hyun-nieAhn and Bruce E. Wampold(2001) conducted a meta analytic study to determine whether the beneficial effects of counseling and psychotherapy are due to the specific ingredients of the treatments or to the factors common in all therapies. The results of the present meta-analytic study is not supportive of the benefits of specific ingredients. This suggests that the benefits of treatments are probably due to the pathways common to all bona fide psychological treatments, such as the healing context, the belief in the rationale for and the efficacy of therapy by the client and by the therapist, the therapeutic alliance, therapeutic procedures consistent with the client's understanding of his or her problems, the development of increased self-efficacy to solve one's problems, and remoralization (Frank \& Frank, 1991; Garfield, 1992; Wampold, 2001). The research evidence supports the notion that the benefits of counseling and psychotherapy are derived from the common factors. For example, it has been shown that the therapeutic alliance, measured at an early stage, accounts for a significant portion of the variability in treatment outcomes (Horvath \& Symonds, 1991; Martin et al, 2000). Moreover, the variance due to therapists within treatments is greater than the variance between treatments, lending primacy to the person of the therapist rather than to the particular treatment (Crits-Christoph et al., 1991; Wampold\&Serlin, 2000). Indeed, the common factors account for about nine times more variability in outcomes than do the specific ingredients (Wampold, 2001). Training models should focus on the common factors as the bedrock of skills necessary to become an effective practitioner. The importance of interviewing skills, establishment of a therapeutic relationship, and the core facilitative conditions in the training of counselors and psychologists is supported by the empirical evidence. Omitting these vital components and training students to conduct solely various empirically supported treatments is contraindicated. These kind of studies are sadly lacking in India. Documentation of cases and scientific methods to quantify or even analyse the qualitative data is essential to authenticate the scientific evidence in this field.

Counseling, as a specialized profession requires to develop certain intervention models that have specific methodologies for different kinds of set up and for different groups of people. The model ought to include specific diagnostic tools and intervention techniques approved by a statutory body. This will not only result in modernization of techniques but also help to bring out certain quantitative analysis which will be more convincing and scientific to the client. Use of equipments to measure stress of the individual or the emotional state of the individual will validate the diagnosis and will increase the receptivity of the client during the following cognitive behavior therapy session. Similarly it is important that counselors also use different assessment schedules for personality, aggression etc that will further authenticate their diagnosis and suggestions for suitable interventions. The basis of psycho neuro immunology- a science which advocates the body mind connection is another important branch that counselors need to be familiar with and apply its basics while treating psycho somatic disorders. The results obtained after successful counseling sessions too require to be quantified in order to present the success of this profession. There is a need to validate the counseling process through scientific research. There is a dearth of research in the field of counseling in India. There is a need for innovative techniques that will continue to be client centred but at the same time prove to bemore scientific. Extensive research both quantitative as well as qualitative, in the various aspects of counseling such as diagnosis , case work, interventions and usage of complimentary healing is the need of the hour. Professionals in 
this field need to work on the scientific projection of this field and also work towards better strategies in promoting mental health in various walks of life.

There are a good number of students, especially the brighter and higher achievers, who feel the need to discuss their blocks, confusions and fears, approach their school/ college counselor and help themselves. Many parents who are frustrated with their child's poor performance or behavior problems approach a counselor as the last resort. They take sessions with a hope that they will finally see a solution for their problem. But even those who do approach a counselor are unaware of its scientific foundation as well as its technical approach. Hence, lot of awareness regarding mental health require to be generated so that the common man is aware of the need to approach a counselor and help himself .Rickwood and Braithwaite (1994), pointed out that having a social network that accepts and encourages help seeking for a problem is necessary for the person to seek help. Children and adolescents need to be educated about the importance of maintaining good mental health in order to maintain positive behavior and best health practices. Maintaining a positive state of mental health is essential for an individual to remain positive in spite of any situation and also to work towards developing the need to climb the ladder of hierarchy of needs as described by Maslow. This awareness will also help them identify and encourage anyone in their social circle to seek help whenever needed. Seeking help from another to some degree means admitting that one cannot deal with the problem on one's own and, as such, can be an admission of inadequacy (Fisher et al., 1982). Thus, a person may decide not to seek help in order to maintain a positive self-image (Miller, 1985). Fear of embarrassment and feelings of inferiority or incompetence have been linked with help-seeking decisions (Nadler, 1991). People are, therefore, more willing to seek help for a mental health problem from general medical doctors than they are from a mental health professional (Christensen et al, 1976). The awareness campaigns and public education need to focus on addressing these problems and convince the general public that their self image comes to no attack by seeking help at the appropriate time. Awareness and maintenance of mental health is crucial to prevent many a social problem and wrong doings. It reduces impulsivity, aggression, vengeance and increases the capacity to analyse, be rational and think logically and behave maturely in all situations. It is also important that supporting professions such as medicine, physiotherapy, dieticians are also educated about the importance of maintenance of mental health as a result of which they may be able to identify the need for counseling in their patients and refer them at the appropriate time.

Research can be a powerful resource building tool in the development or enhancement of counseling services Studying counseling in other countries requires researchers to focus on culturally relevant interventions and to avoid the assumption that Western counseling approaches will be as effective or appropriate for use in other areas of the world. (Wendy J. Hoskins and Holly C. Thompson,2009). The same holds true for Indian counselors as the country which is extremely diverse in culture and beliefs. Goa in India is a small state where the local people believe in spirits and superstitions. The counselor needs to understand their belief system and work through the same while providing suggestions and interventions. Mumbai, a metropolitan city, individuals here are used totravelling and hence have no inhibitions travelling for one hour to reach a counselor but are extremely rigid with regard to time as their schedules go by the timings of the local trains and they can become extremely non receptive if the timing is not given importance. Chennai in south, is very flexible with regard to time but very closed and hence acceptance of a counselor from the northern states may be difficult for a local. In any city in India, counseling of children and adolescents will mostly have to include the parents too ( unlike in the West) as here, parents have an active role in the life of their children . Even in college, many a parent visit the counselor along with the student even though he / she may legally be an adult. India is also a country where many complimentary therapies and healing systems are very popular. Studying the same scientifically and approving the use of same along with counseling will also prove to be beneficial and increase the receptivity of the clients. The techniques followed here need to be adapted to the culture and belief system of the mind set of people here. Students express a comfort zone if the counselor belongs to the same geographical region and or speaks the same language. Many students approach the counselor whom they are able to relate to as a mother figure.

\section{Conclusion}

Counseling in India needs a facelift and the same may be achieved by promoting the same in a scientific manner for which a lot of research needs to be conducted in that field. It also needs to be authenticated by a regulating body .Simultaneously, the profession needs to be developed in a more structured manner with certain quantifiable specifications that will be ableto project the diagnosis and interventions in a more tangible manner . Counselors also need to involve in active public education and awareness regarding the importance of maintaining positive mental health and take practical steps to help the clients overcome the avoidance behavior and seek help. Group work along with individual counseling needs to be promoted for commonly experienced problems. Institutions for their part need to recognize the professionalism in the field and respect the need for confidentiality. They also need to be receptive to public education and understand the skills in the profession 
and refer individuals early instead trying to solve things themselves. The management needs to compartmentalize the decisions of punishable offense and the services being provided through counseling that will work as intervention for certain undesirable behavior. Complimentary healing systems found to be scientific, need to be validated and encouraged as supportiveinterventions in counseling sessions. Counselors as well as the common public need to give priority to preventive interventions rather than remedial . School and college counseling need to be considered as professional departments that contribute towards maintaining mental health of the members of the institution which in turn provides better results, better performance and better workplace environment .

Counseling as a profession, can go a long way in maintaining and restoring mental health of individuals and society. Indian society, today is in dire need for serious professionals in this field . Counselors can provide sure solutions to the Indian society plagued with various mental stress and emotional turbulences. It is surely the need of the hour. With a little scientific touch to the diagnosis and intervention and regular systematic documentation and recording, this profession will soon be able to take an equal place with other health service professions.

\section{References :}

[1]. Alison Salloum, Lisa Avery,Ronald P Mcclain;(2001); Group Psychotherapy for Adolescent Survivors of Homicide Victims: A Pilot Study; Journal of the American Academy of Child \& Adolescent Psychiatry;40(11);1261-1267

[2]. Andrews, G., Issakidis, C., \& Carter, G.; (2001); Shortfall in Mental Health Service Utilization; British Journal of Psychiatry; 179; $417-425$.

[3]. Bayer, J. K., \&Peay, M. Y.;(1997); Predicting Intentions to Seek Help from Professional Mental Health Services; Australian and New Zealand Journal of Psychiatry; 31; 504-513

[4]. Bergin, A. E., \& Garfield, S. L. (Eds.); (1994); Handbook of Psychotherapy and Behavior Change; (4th ed.); New York: Wiley.

[5]. Bruce E. Wampold, Gregory W. Mondin, Marcia Moody, Frederick Stich, Kurt Benson, and Hyun-nieAhn;(1997); A Meta-Analysis of Outcome Studies Comparing Bona Fide

[6]. Psychotherapies: Empirically, "All Must Have Prizes"; Psychological Bulletin; 122;(3); 203-215

[7]. Cepeda-Benito, A., \& Short, P. ;(1998); Self-Concealment, Avoidance of Psychological Services, and Perceived Likelihood of Seeking Help; Journal of Counseling Psychology; 45; 58-64.

[8]. Ciarrochi, J. V., \& Deane, F. P. ;(2001); Emotional Competence and Willingness to Seek Help from Professional and Nonprofessional Sources; British Journal of Guidance and Counseling; 29; 233-246.

[9]. Clara E. Hill and Maureen M. Corbett;1993; A Perspective on the History of Process and Outcome Research in Counseling Psychology; Journal of Counseling Psychology; 40( 1); 3-24

[10]. Conyne, R. K.; (1991); Gains in Primary Prevention: Implications for the counseling profession;

[11]. Journal of Counseling and Development; 69;277-279

[12]. David L. Vogel, Stephen R. Wester, and Lisa M. Larson;(2007); Avoidance of Counseling: Psychological Factors That Inhibit Seeking Help; Journal of Counseling \& Development;85;410-424

[13]. David L. Vogel, Stephen R. Wester, Meifen Wei and Guy A. Boysen;(2005); The Role of Outcome Expectations and Attitudes on Decisions to Seek Professional Help;Journal of Counseling Psychology; 52(4);459-470

[14]. Deane, F. P., \& Todd, D. M.; (1996); Attitudes and Intentions to Seek Professional Psychological Help for Personal Problems or Suicidal Thinking; Journal of College Student Psychotherapy; 10; 45-59.

[15]. Derald Wing Sue, Patricia Arredondo and Roderick J. Mcdavis; (1992); Multicultural Counseling Competencies and Standards: A Call to the Profession;Journal of Counseling \& Development; 70;477-487

[16]. Diala, C., Muntaner, C., Walrath, C., Nickerson, K. J., LaVeist, T. A.,\& Leaf, P. J. ;(2000); Racial Differences in Attitudes toward Professional Mental Health Care and in the use of Services; American Journal of Orthopsychiatry; 70; 455-464.

[17]. Dr. C R Chandrashekar, Dr B M Suresh, Dr K V Kishore Kumar, Dr Sundar Moily,DrAhalyaRaghuram, Dr R Parthsarathy,Dr K Sekhar, Dr Romate John;(2007);Manual on Students Counseling for College Teachers;National Institute of Mental Health and Neuro Sciences, NIMHANS, Bangalore;

[18]. Dr Madhu Agarwal; Family Counseling Centres: A Study;(2011); National Institute of Public Cooperation and Child Development, Lucknow

[19]. Dubow, E. F., Lovko, K. R., \&Kausch, D. F.; (1990); Demographic Differences in Adolescents' Health Concerns and Perceptions of Helping Agents;Journal of Clinical and Consulting Psychology;19; 44-54.

[20]. Edward A. Delgado-Romero,NallelyGalván,PeggyMaschino,Marcy Rowland;(2005); Race and Ethnicity in Emperical Counseling and Counseling Psychology Research : a 10 Year Review;The Counseling Psychologist;33(4);419-448

[21]. Edward W. Gondolf;(2004); Evaluating batterer counseling programs: A difficult task

[22]. showing some effects and implications; Aggression and Violent Behavior; 9; 605-631

[23]. Elizabeth Reynolds Welfel, Lewis E Patterson;2005;The Counseling Process A Multitheoretical Integrative Approach;Thomson Brooks/Cole

[24]. Fretz, B. R., \& Simon, N. P.; (1992);Professional issues in counseling psychology: Continuity,

[25]. change, and challenge. In S. B. Brown \& R. W. Lent (Eds.); Handbook of Counseling Psychology;(pp. 3-36). New York: John Wiley

[26]. Gale, A.U. \& Austin, B.D.; (2003); Professionalism's challenges to professional counselors' collective identity; Journal of Counseling Development; 81(1); 3-10

[27]. Greg Brigman, Chari Campbell;(2003); Helping Students Improve Academic Achievement andSchool Success Behavior; ASCA,Professional School Counseling;7(2),91-99

[28]. Elizabeth M. Vera,Suzette L. Speight;(2003); Multicultural Competence, Social Justice, and Counseling Psychology: Expanding Our Roles; The Counseling Psychologist; 31( 3); 253-272

[29]. Hinson, J. A., \& Swanson, J. L.; (1993); Willingness to Seek Help as a Function of Self-Disclosure and Problem Severity; Journal of Counseling \& Development; $71 ; 465-470$.

[30]. Hyun-nieAhn and Bruce E. Wampold;(2001); Where Oh Where Are the Specific Ingredients? A Meta-Analysis of Component Studies in Counseling and Psychotherapy; Journal of Counseling Psychology;48(3);251-257

[31]. John R. Jordan, Roberta. Neimeyer;(2003);Does Grief Counseling Work?;Death Studies, Taylor and Francis, Inc;24,765-786 
[32]. Jourard, S. M ;(1964); The Transpersonal Self; New York: Van Nostrand

[33]. Kleist, D. M.,\&White, L. J.; (1997); The Values of Counseling: A Disparity between a Philosophyof Prevention in Counseling and Counselor Practice and Training; Counseling and Values, 41, 128-140.

[34]. Komiya, N., Good, G. E., \& Sherrod, N. B.; (2000); Emotional Openness as a Predictor of College Students' Attitudes Toward Seeking Psychological Help; Journal of Counseling Psychology,47, 138-143.

[35]. Kushner, M. G., \&Sher, K. J.; (1989); Fears of Psychological Treatment and its Relation to Mental Health Service Avoidance; Professional Psychology: Research and Practice; 20; 251-257.

[36]. Lanning, W.;(1990);An educator/practitioner model for counselor education doctoral programs; Counselor Education \& Supervision; 30;163-169.

[37]. Louise F. Fitzgerald and Lawrence J. Hubert;(1987); Multidimensional Scaling: Some Possibilitiesfor Counseling Psychology; Journal or Counseling Psychology;34(4); 469-480

[38]. Miller, W. R. (1985);Motivation for treatment: A review with special emphasis on alcoholism; Psychological Bulletin; 98 ; 84-107.

[39]. Myers, J. E.;(1992); Wellness, Prevention, Development: The Cornerstone of the Profession; Journal of Counseling and Development; 71; 136-139

[40]. Nadler, A.; (1991); Help-seeking behavior: Psychological Costs and Instrumental Benefits; In M. S. Clark (Ed.), Prosocial behavior; Review of personality and social psychology ; Sage; Vol. 12; 290-311

[41]. Nelson, G. D., \&Barbaro, M. B.; (1985); Fighting the Stigma: A Unique Approach to Marketing Mental Health.;Marketing Strategies for Human and Social Service Agencies; 2; 89-101.

[42]. Neukrug, E.;(2003);The world of the counselor: An introduction to the counseling profession;New York: Brooks/Cole.

[43]. Patricia A. Frazier, Andrew P. Tix, Kenneth E. Barron;(2004); Testing Moderator and Mediator Effects in Counseling Psychology Research;51(1);115-134

[44]. Rickwood, D. J., \& Braithwaite, V. A.; (1994); Social-psychological factors affecting help-seeking for emotional problems; Social Science and Medicine; 39; 563-572.

[45]. Robert J. Petrella, Chastity N. Lattanzio;(2002); Does counseling help patients get active? Systematic review of the literature;Canadian Family Physician, 48

[46]. S Narayana Rao;1991;Counseling and Guidance; TataMcgraw -Hill Publishing Company ltd

[47]. Sue, D. W., \& Arredondo, P. (1992);Multicultural Counseling Competencies and Standards: A Call to the Profession; Journal of Multicultural Counseling \& Development; 20; 64-89.

[48]. Tinsley, H. E. A., Brown, M. T., de St. Aubin, T. M., \&Lucek, J. ;(1984); Relation Between Expectancies for a Helping Relationship and Tendency to Seek Help from a Campus Provider; Journal of Counseling Psychology; 31; 149-160.

[49]. Vogel, D. L., \&Wester, S. R.; (2003); To Seek Help or Not to Seek Help:The Risks of Self-Disclosure; Journal of Counseling Psychology;50; 351-361.

[50]. Vogel, D. L., Wester, S. R., Wei, M., \&Boysen, G. A. (2005); The Role of Outcome Expectations and Attitudes on Decisions to Seek Professional Help; Journal of Counseling Psychology; 52; 459-470.

[51]. Weinrach, S. G., Thomas, K. R., \& Chan, F.; (2001); The Professional Identity of Contributors to the Journal of Counseling \& Development: Does it matter?; Journal of Counseling \& Development; 79; 166-170

[52]. Wendy J. Hoskins and Holly C. Thompson; (2009); Promoting International Counseling Identity: The Role of Collaboration, Research, and Training; American Counseling Association Annual

[53]. Conference and Exposition, March 19- 23, Charlotte, North Carolina.

[54]. Wills, T. A.; (1992); The Helping Process in the Context of Personal Relationship; In S. Spacapan\& S. Oskamp (Eds.); Helping and Being Helped (pp. 17-48). Newbury Park, CA: Sage. 